\title{
Investigation of stability of cold pressed linseed (Linum usitatissimum L.) oil
}

\author{
Zorica Drinić ${ }^{1, *}$, Jelena Mudrić ${ }^{1}$, Gordana Zdunić ${ }^{1}$, Dubravka Bigović ${ }^{1}$, ANd Katarina \\ S̆AVIKIN $^{1}$
}

${ }^{1}$ Institute for Medicinal Plants Research “Dr. Josif Pančić”, Tadeuša Košćuška 1, Belgrade, Serbia

*Corresponding author: zdrinic@mocbilja.rs

Received: November 11, 2019

Accepted: December 5, 2019

Published on-line: December 9, 2019

Published: December 25, 2019

\begin{abstract}
The stability of linseed (Linum usitatissimum) oil has been investigated through the exposition of two different samples, linseed oil without antioxidant and linseed oil with roesemary (Rosmarinus officinalis) extract, to ambient temperature conditions $\left(25^{\circ} \mathrm{C}\right)$ and refrigerator temperature conditions $\left(4{ }^{\circ} \mathrm{C}\right)$. The oxidation degree of linseed oil was characterized by acid value, peroxide value, which present value for determination primary oxidation processes, and TBARS value expressed through the percent of inhibition, which present value for determination secondary oxidation processes. Acid value in all investigated samples was in the range from 1.90 to $1.97 \mathrm{~mL} / \mathrm{g}$. Peroxide value was in the range from 1.27 to $3.27 \mathrm{~mL} / \mathrm{g}$. The percent of inhibition of oxidation in investigated samples was from 10.41 to $11.10 \%$. The storage conditions influence primary oxidation processes in oil, while the presence of rosemary extract influences secondary oxidation processes.
\end{abstract}

Key words: flax, linseed oil, acid value, peroxide value, TBARS value

http://dx.doi.org/10.5937/leksir1939040D

\section{INTRODUCTION}

Linseed (Linum usitatissimum L.), also known as flax, is widely distributed annual plant from family Linaceae. The main products of this herbaceous plant are seeds, oil and fibers. Linseed contains about $36-40 \%$ oil which is a rich source of polyunsaturated fatty acid, phytosterols, phospholipids, and vitamins (Popa et al., 2012; Rudnik et al., 2001). The dominant fatty acid in linseed oil is $\alpha$-linolenic acid and its content is more than $40 \%$ (Michotte et al., 2011; Symoniuk et al., 2017). The $\alpha-$ linolenic acid is a $\omega-3$ and essential fatty acid and it is reported that the higher intake of it can decrease the production of proinflammatory molecules and consequently the risk of cardiovascular diseases and cancer is reduced (Hasiewicz-Derkacz et al., 2015). Moreover, consumption of $\omega-3$ polyunsaturated fatty acids has prophylactic and therapeutic benefits in case of various diseases, such as type 2 diabetes, neurodegenerative diseases, mental and hormonal disorders (Lange et al., 2019; Simopoulos, 2002). On the other hand, polyunsaturated fatty acids are highly prone to oxidation during the processing, storage and usage. Oxidation processes lead to the deterioration of oils and the formation of toxic compounds, such as lipid hydroperoxides, aldehydes, ketones and radicals with harmful effects on the biological molecules (Choe and Min, 2006; Tańska et al., 2016). Furthermore, it is reported that the production of $\omega-3$ peroxides can be related to the lipid membrane peroxidation, cell damage, and oxidative stress. Prevention of oil oxidation processes and prolonging shelf life is possible by adding natural or synthetic antioxidants (tocopherol, butylhydroxyanisole, butylhydroxytoluene, tert-butylhydroquinone) (van Ruth et al., 2001). Today, there is an increased interest in replacing synthetic antioxidants with natural ones. Phenolic compounds, which are widely distributed in the plant kingdom, are well known as antioxidants (Jovanović et al., 2018). It is reported that hydrophilic phenolic compounds are more efficient than hydrophobic synthetic antioxidants in preventing oxidation of polyunsaturated fatty acids. Furthermore, caffeic acid has been reported as a more efficient antioxidant than butylhydroxyanisole in sunflower and corn oil (De Leonardis et al., 2003; Roussis et al., 2008). Myricetin reduced the loss of linoleic and $\alpha$-linoleic acid in rapeseed oil (Chen et al., 1996).

Rosemary (Rosmarinus officinalis L.) has been attracted a lot of attention as a source of antioxidants. Antioxidant activity of rosemary is attributed to their phenol diterpenes such as carnosic acid, carnosol and rosmarinic acid (Erkan et al., 2008). Rosemary extract has been approved for use as a food additive in European Union countries by the European Food Safety Authority (EFSA) in 2008. European Commission authorized the use of rosemary extract in several foodstuffs, including vegetable oil. Allowed concentration of rosemary extract is 30 or $50 \mathrm{mg} / \mathrm{L}(\mathrm{kg})$ for oils, depending on their type and purpose. Moreover, rosemary extract (E 392) has been approved for use in Republic of Serbia by Regulations on food additives, 
published in the Službeni glasnik RS, 53/2018. Allowed concentration E 392 in Republic of Serbia is the same as in the European Union.

Taking into account previously mentioned, the aim of this work was to investigate the influence of rosemary extract and storage conditions on the stability of cold-pressed linseed oil. The oxidation degree of linseed oil was characterized by acid value, peroxide value, and TBARs value.

\section{MATERIALS AND METHODS}

\subsection{Standards and reagents}

Acetic acid, hydrochloric acid, ethanol and distilled water were purchased from Zorka Pharma (Serbia). Thiobarbituric acid and 3-chloroacetic acid were purchased from Sigma Chemicals Co. (USA). Sodium hydroxide $(0.1 \mathrm{~mol} / \mathrm{L})$ and sodium thiosulphate were purchased from Alfapanon (Serbia). Petroleum ether, $p$-anisidine and iso-octane were purchased from Fisher Chemical (UK). Chloroform and potassium iodide were purchased from Carlo Erba (Spain). All chemicals used in the experimental procedure were of analytical grade purity.

\subsection{Plant material}

Aerial parts of rosemary (Rosmarinus officinalis L.) were collected in June 2018 from the collection of the Institute for Medicinal Plant Research "Dr. Josif Pančić", Belgrade. Voucher samples are stored in the Herbarium of the Institute of Botany and Botanical Garden "Jevremovac", Faculty of Biology, University of Belgrade; voucher No. (17487). Linseed (L. usitatissimum L.) seeds were purchased from Institute for Medicinal Plant Research "Dr. Josif Pančić", Belgrade (product serial number 19750718, 19690718).

\subsection{Rosemary extract preparation}

Rosemary leaves were ground in laboratory mill. The extraction of rosemary leaves was performed in an ultrasonic bath $(40 \mathrm{kHz})$ at $50{ }^{\circ} \mathrm{C}$, according to the procedure suggested by Wang et al. (2018). Ethanol in the concentration of $80 \%(\mathrm{v} / \mathrm{v})$ was used as a solvent, while plant/solvent ratio was 1:20. The extraction time was 30 minutes. Obtained liquid extract was evaporated by a vacuum evaporator under $50{ }^{\circ} \mathrm{C}$. The obtained dry extract was collected and stored.

\subsection{Characterization of rosemary extract}

\subsubsection{Total phenolic content}

Folin-Ciocalteu (FC) colorimetric method was used for determination of the total phenolic content (TPC) in extracts by modified spectrophotometric method (Balijagić et al., 2012; Waterman and Mole, 1994). The results were expressed as milligrams of gallic acid equivalents per gram of dry extract (mg GAE/g).

\subsubsection{Radical scavenging activity}

Radical scavenging activity of the extract was determined by DPPH (2.2-diphenyl-1-picrylhydrazyl) assay (Blois, 1958) with slight modifications. One hundred $\mu \mathrm{L}$ of the $50 \mathrm{mg} / \mathrm{kg}$ extract solution in $80 \%$ ethanol and $1400 \mu \mathrm{L}$ of methanolic solution of DPPH $(40 \mu \mathrm{g} / \mathrm{mL})$ were mixed and incubated for 20 minutes in the dark at room temperature. The absorbance of the reaction mixture was measured at $517 \mathrm{~nm}$. For the control one hundred of $80 \%(\mathrm{v} / \mathrm{v})$ ethanol was used instead of extract solution. The percentage of neutralization of DPPH radical was calculated using the equation:

$$
\text { Inhibition of DPPH radical (\%) }=100-\left(\frac{A_{\text {sample }}}{A_{\text {control }}} \times 100\right)
$$

where $A_{\text {sample }}$ is the absorbance of the test sample and $A_{\text {control }}$ is the absorbance of control.

\subsection{Linseed seed oil extraction}

Linseed seed oil was obtained by the domestic oil press (OP650W, Gorenje Group, Slovenia). Cold pressing technology was applied and temperature was below $50{ }^{\circ} \mathrm{C}$ during the pressing. The obtained oil was characterized in terms of acid value and peroxide value, immediately. Two samples, linseed seed oil without antioxidant and linseed seed oil with rosemary extract in concentration according to the EFSA ( $50 \mathrm{mg} / \mathrm{kg}$ ), were prepared. Both samples were stored at following conditions: in refrigerator $\left(4^{\circ} \mathrm{C}\right)$ and at ambient temperature $\left(25^{\circ} \mathrm{C}\right)$ for a month. The oil samples were characterized in terms of acid value, peroxide value and TBARS value.

\subsection{Characterization of linseed oil}

\subsubsection{Acid value}

The acid value (Ia) was determined according to the procedure of the European pharmacopeia (Ph.Eur.8.0., 2013). Oil (10 g) was dissolved in $50 \mathrm{~mL}$ of a mixture of equal volumes of ethanol and petroleum ether. Phenolphthalein was used as an indicator. The mixture was titrated with $0.1 \mathrm{M}$ potassium hydroxide until pink color persists for at least $15 \mathrm{~s}$. Blank test was carried out under the same conditions. Acid value was calculated using the following equation:

$$
\mathrm{Ia}=\frac{5.61 \times n}{m}
$$

where $n$ is the difference between the volume of potassium hydroxide required for titration of the oil sample and volume of potassium hydroxide required for titration of blank test $(\mathrm{mL})$ and $m$ is mass of oil sample (g). Acid value was expressed as $\mathrm{mL}$ of potassium hydroxide per $1 \mathrm{~g}$ of the oil $(\mathrm{mL} / \mathrm{g})$.

\subsubsection{Peroxide value}

The peroxide value (Ip) was determined according to the method A of the European pharmacopeia (Ph.Eur.8.0., 2013) with slight modification. Oil ( $5 \mathrm{~g}$ ) was dissolved in $50 \mathrm{~mL}$ mixture of chloroform and ethanol in ratio 2:3. Potassium iodide $(1 \mathrm{~mL})$ was added and shaked for $1 \mathrm{~min}$. Than was added 100 $\mathrm{mL}$ of water. The mixture was titrated with $0.01 \mathrm{M}$ sodium thiosulphate until yellow color was almost discharged. Starch solution $(5 \mathrm{~mL})$ was added and titration was continuing until color is discharged. Blank test was carried out under the same conditions. Peroxide value was calculated using the following equation:

$$
\mathrm{Ip}=\frac{10 \times\left(n_{1}-n_{2}\right)}{m}
$$

where $n_{1}$ is the volume of potassium thiosulphate required for titration of the oil sample, $n_{2}$ is volume of potassium thiosulphate required for titration of blank test (mL), and $m$ is mass of oil sample (g). Peroxide value was expressed as $\mathrm{mL}$ of potassium thiosulphate per $1 \mathrm{~g}$ of the oil (mL/g).

\subsubsection{TBARS value}

Thiobarbituric acid reactive substances (TBARS) were determined according to the method described by Buege and Aust (1978). The thiobarbituric acid solution was obtained by dissolving $0.375 \mathrm{~g}$ thiobarbituric acid in $100 \mathrm{~mL} 0.25 \mathrm{M}$ solution of hydrochloric acid in which $15 \mathrm{~g}$ of 3-chloroacetic acid was previously dissolved. Thiobarbituric acid solution $(2.5 \mathrm{~mL})$ was added in $0.5 \mathrm{~g}$ oil, subsequently heated in a boiling water bath $\left(95-100{ }^{\circ} \mathrm{C}\right)$ for $10 \mathrm{~min}$, cooled by water and then sonicated for $30 \mathrm{~min}$. After the sonication mixture was centrifuged at $3000 \mathrm{rpm}$ for $10 \mathrm{~min}$. The absorbance of the supernatant was measured at $532 \mathrm{~nm}$. TBARS value was expressed through percent inhibition of oxidation and calculated using the following equation: 

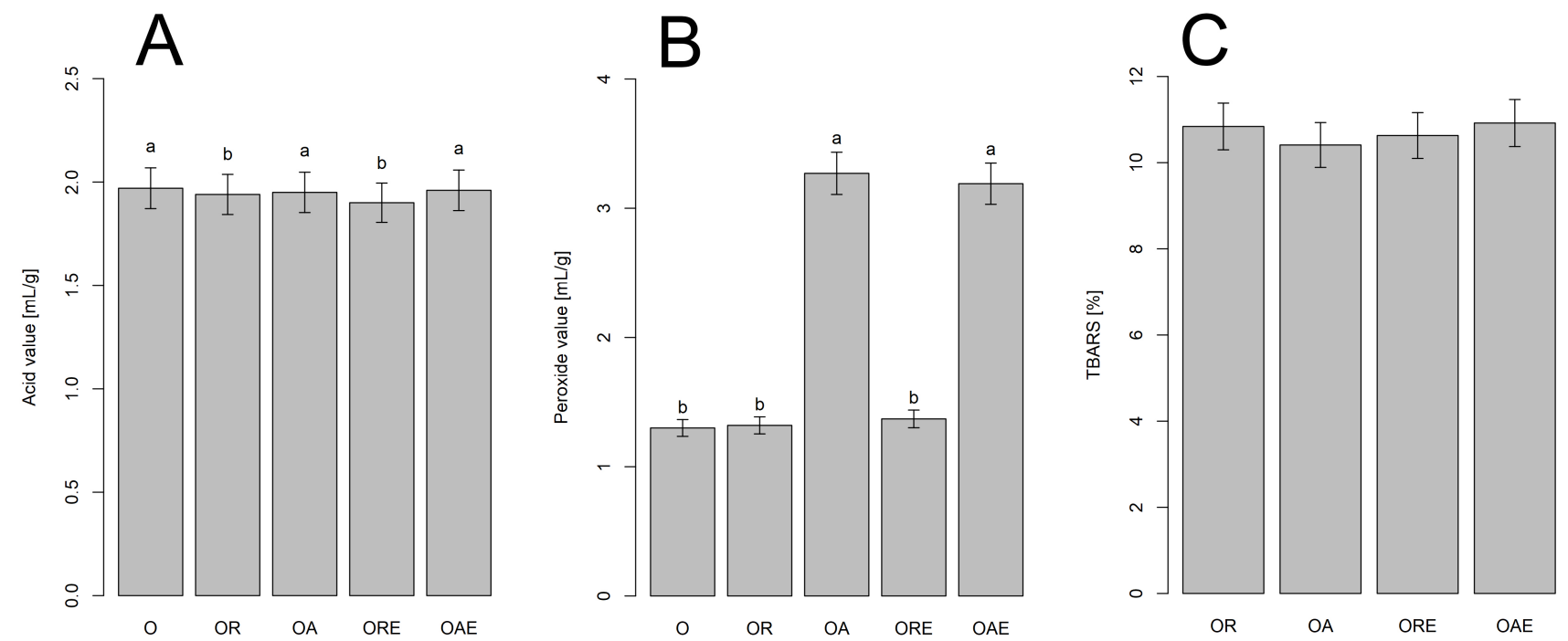

Fig. 1. Quality parameters of linseed oil; acid value (A), peroxide value (B) and TBARS (C) for investigated samples (O - linseed oil characterized immediately, OR - linseed oil without rosemary extract stored in refrigerator, OA - linseed oil without rosemary extract stored at ambient temperature, ORE - linseed oil with rosemary extract stored in refrigerator, OAE - linseed oil with rosemary extract stored at ambient temperature)

$$
\text { Inhibition of oxidation (\%) }=\frac{1-A_{\text {sample }}}{A_{\text {control }}} \times 100
$$

where $A_{\text {sample }}$ is the absorbance measured in the oil sample and $A_{\text {control }}$ is the absorbance measured in total oxidized oil sample without the protection of antioxidants.

\subsection{Statistical analyses}

All experimental measurements were carried out in triplicate and the results are expressed as the average of three measurements \pm standard deviation. Differences among mean values were estimated by post hoc Duncan's MR test. Statistical analysis was performed using the MS Office Excel v. 2010, while charts were produced in R Base Plot environment (CRAN).

\section{RESULTS AND DISCUSSION}

\subsection{Characterization of rosemary extract}

Rosemary dry extract, which was used for the stabilization of linseed seed oil was characterized by high TPC (347.74 mg GAE/g). Phenolic components are the main antioxidant compounds in the rosemary extract and because of that TPC was a good indicator of extract antioxidant activity. Furthermore, the effect of rosemary extract on the stabilization of linseed oil is a result not only of its phenolic components, but also a synergistic effect with self-containing tocopherols in the oil (Wang et al., 2018). The percentage of neutralization of DPPH radical of extract in a concentration used for stabilization of oil (50 $\mathrm{mg} / \mathrm{kg}$ ) was $4.77 \%$. Wang et al. (2018) reported that the rosemary extract obtained by the same method as in our study has shown favorable oxidative stability and preservation efficacy in comparison to the $\alpha$-tocopherol and butylhydroxytoluene in linseed oil.

\subsection{Effect of the presence of rosemary extract and storage conditions on oil stability \\ 3.2.1. Acid value}

The acid value measures free fatty acids, which indicates the extent of hydrolytic rancidity. Cleavage of a free fatty acid from a parent molecule shows hydrolytic breakdown and is often used in whole biological systems as an indication of stress. According to the Ph.Eur.8.0. (2013) the maximum acid value of virgin linseed oil, which present fatty oil obtained by cold expression from ripe seeds of linseed is $4.5 \mathrm{~mL} / \mathrm{g}$. Acid value in all investigated samples was less than $4.5 \mathrm{~mL} / \mathrm{g}$ and it was in the range from 1.90 to $1.97 \mathrm{~mL} / \mathrm{g}$. Lower and statistically significantly different acid values after one month of storage were in the samples with and without rosemary extract stored in the refrigerator (Fig. 1A). Compared two samples stored at a different temperature it can be concluded that storage temperature has an influence on stability linseed oil in terms of acid value for the investigated storage period.

\subsubsection{Peroxide value}

Primary oxidation processes were expressed through peroxide value. In general, the lower the peroxide value, the better the quality of the oil. The maximum allowed peroxide value for linseed seed oil according to the Ph.Eur.8.0. (2013) is $15 \mathrm{~mL} / \mathrm{g}$. Peroxide value in all investigated samples was less than 15 $\mathrm{mL} / \mathrm{g}$ and it was in the range from 1.27 to $3.27 \mathrm{~mL} / \mathrm{g}$. The peroxide value in linseed oil samples stored in the refrigerator was not significantly different from peroxide value determined in fresh oil, and it was significantly lower than peroxide value in oil samples stored at ambient temperature (Fig. 1B). The storage conditions significantly affected peroxide value. The peroxide value was higher about two times in samples stored at ambient temperature than samples stored in the refrigerator.

\subsubsection{TBARS value}

The TBARS value is a method to investigate secondary oxidative aldehyde products. One of the compounds produced from secondary oxidation in lipids is MDA (malondialdehyde) which can be measured by the TBARS method (Mohd Azman et al., 2014). The percent of inhibition of oxidation in investigated samples was from $10.41 \pm 0.52$ to $11.10 \pm 0.32 \%$. The $\%$ inhibition of oxidation did not differ statistically in investigated samples (Fig. 1C).

\section{CONCLUSION}

Effect of the presence of rosemary extract and storage conditions on stability of linseed oil was investigated. The storage conditions have influence on primary oxidation processes 
in oil for the investigated storage period (1 month), while presence of rosemary extract has no influence on oxidation processes. From the present study it can be concluded that storage of linseed oil at refrigerator temperature can improve stability of linseed oil.

\section{ACKNOWLEDGMENTS}

This work was supported by the Ministry of Education, Science and Technological Development of the Republic of Serbia, project number III 46013.

\section{REFERENCES}

Balijagić, J., Janković, T., Zdunić, G., Bošković, J., Šavikin, K., Goćevac, D., Stanojković, T., Jovančević, M. and Menković, N. (2012). Chemical profile, radical scavenging and cytotoxic activity of yellow gentian leaves (Genitaneae luteae folium ) grown in northern regions of Montenegro, Natural Product Communications 7(11): 1934578X1200701.

Blois, M. S. (1958). Antioxidant determinations by the use of a stable free radical, Nature 181(4617): 1199-1200.

Buege, J. A. and Aust, S. D. (1978). Microsomal lipid peroxidation, Methods in Enzymology, Vol. 52, Elsevier, pp. 302-310.

Chen, Z., Chan, P., Ho, K., Fung, K. and Wang, J. (1996). Antioxidant activity of natural flavonoids is governed by number and location of their aromatic hydroxyl groups, Chemistry and Physics of Lipids 79(2): 157-163.

Choe, E. and Min, D. B. (2006). Mechanisms and factors for edible oil oxidation, Comprehensive Reviews in Food Science and Food Safety 5(4): 169-186.

De Leonardis, A., Macciola, V. and Di Rocco, A. (2003). Oxidative stabilization of cold-pressed sunflower oil using phenolic compounds of the same seeds, Journal of the Science of Food and Agriculture 83(6): 523-528.

Erkan, N., Ayranci, G. and Ayranci, E. (2008). Antioxidant activities of rosemary (Rosmarinus officinalis L.) extract, blackseed (Nigella sativa L.) essential oil, carnosic acid, rosmarinic acid and sesamol, Food Chemistry 110(1): 76-82.

Hasiewicz-Derkacz, K., Kulma, A., Czuj, T., Prescha, A., Żuk, M., Grajzer, M., Łukaszewicz, M. and Szopa, J. (2015). Natural phenolics greatly increase flax (Linum usitatissimum) oil stability, BMC Biotechnology 15(1): 62.

Jovanović, M., Milutinović, M., Kostić, M., Miladinović, B., Kitić, N., Branković, S. and Kitić, D. (2018). Antioxidant capacity of pineapple (Ananas comosus (L.) Merr.) extracts and juice, Lekovite sirovine (38): 27-30.

Lange, K. W., Nakamura, Y., Gosslau, A. M. and Li, S. (2019). Are there serious adverse effects of omega-3 polyunsaturated fatty acid supplements?, Journal of Food Bioactives 7.

Michotte, D., Rogez, H., Chirinos, R., Mignolet, E., Campos, D. and Larondelle, Y. (2011). Linseed oil stabilisation with pure natural phenolic compounds, Food Chemistry 129(3): 12281231.

Mohd Azman, N. A., Segovia, F., Martínez-Farré, X., Gil, E. and Almajano, M. P. (2014). Screening of antioxidant activity of Gentiana lutea root and its application in oil-in-water emulsions, Antioxidants 3(2): 455-471.

Ph.Eur.8.0. (2013). European Pharmacopoeia 8.0., Council of Europe, Strasbourg Cedex, France.
Popa, V.-M., Gruia, A., Moldovan, C., Bordean, D. and Mateescu, C. (2012). Fatty acids composition and oil characteristics of linseed (Linum usitatissimum L.) from Romania, Journal of Agroalimentary Processes and Technologies p. 5.

Roussis, I. G., Tzimas, P. C. and Soulti, K. (2008). Antioxidant activity of white wine extracts and some phenolic acids toward corn oil oxidation, Journal of Food Processing and Preservation 32(4): 535-545.

Rudnik, E., Szczucinska, A., Gwardiak, H., Szulc, A. and Winiarska, A. (2001). Comparative studies of oxidative stability of linseed oil, Thermochimica Acta 370(1-2): 135-140.

Simopoulos, A. (2002). The importance of the ratio of omega6/omega-3 essential fatty acids, Biomedicine \& Pharmacotherapy 56(8): $365-379$

Symoniuk, E., Ratusz, K. and Krygier, K. (2017). Oxidative stability and the chemical composition of market cold-pressed linseed oil: Market linseed oil quality, European Journal of Lipid Science and Technology 119(11): 1700055.

Tańska, M., Roszkowska, B., Skrajda, M. and Dabrowski, G. (2016). Commercial cold pressed flaxseed oils quality and oxidative stability at the beginning and the end of their shelf life, Journal of Oleo Science 65(2): 111-121.

van Ruth, S. M., Shaker, E. S. and Morrissey, P. A. (2001). Influence of methanolic extracts of soybean seeds and soybean oil on lipid oxidation in linseed oil, Food Chemistry 75(2): 177184.

Wang, Y.-Z., Fu, S.-G., Wang, S.-Y., Yang, D.-J., Wu, Y.-H. S. and Chen, Y.-C. (2018). Effects of a natural antioxidant, polyphenol-rich rosemary (Rosmarinus officinalis L.) extract, on lipid stability of plant-derived omega-3 fatty-acid rich oil, LWT 89: 210-216.

Waterman, P. G. and Mole, S. (1994). Analysis of Phenolic Plant Metabolites, 1st edn, Wiley-Blackwell, Oxford ; Boston. 